\title{
Molecularly imprinted polymer for 2, 4-dichlorophenoxyacetic acid prepared by a sol-gel method
}

\author{
YANLI SUN* \\ Department of Chemistry and Chemical Engineering, Heze University, Heze 274015, China \\ e-mail: aspiration8502@163.com
}

MS received 21 January 2014; revised 3 April 2014; accepted 10 April 2014

\begin{abstract}
Based on a sol-gel procedure, a molecularly imprinted polymer (MIP) for 2, 4-dichlorophenoxyacetic acid (2, 4-D) was synthesized, using phenyltrimethoxysilane (PTMOS), aminopropyltriethoxysilane (APTES) as monomers and tetraethoxysilane (TEOS) as cross-linking agent. In addition to the amount of the template, some factors in the sol-gel process: TEOS/APTES/PTMOS molar ratio, $\mathrm{H}_{2} \mathrm{O} / \mathrm{Si}$ molar ratio, $\mathrm{CH}_{3} \mathrm{CH}_{2} \mathrm{OH} / \mathrm{Si}$ molar ratio, etc. were investigated in detail. Results show that the optimum conditions for the preparation of the MIPs were 20:1.5:1 (TEOS: APTES: PTMOS), ca. $4\left(\mathrm{H}_{2} \mathrm{O} / \mathrm{Si}\right)$, ca. $4\left(\mathrm{CH}_{3} \mathrm{CH}_{2} \mathrm{OH} / \mathrm{Si}\right)$, respectively. Effects of various parameters involved in the adsorption process of 2, 4-D on MIP such as incubation time, $\mathrm{pH}$, etc. were also evaluated. It is found that the adsorption attained equilibrium within $3 \mathrm{~h}$, the optimum $\mathrm{pH}$ for adsorption was about 7 and the adsorption obeyed Langmuir model. Test results also demonstrated that the present MIP for 2, 4-D had large adsorption capacity (the maximum adsorption concluded from Langmuir model reached $243.3 \mathrm{mg} / \mathrm{g}$ ) and good selectivity.
\end{abstract}

Keywords. Molecular imprinting; sol-gel; 2, 4-dichlorophenoxyacetic acid; adsorption

\section{Introduction}

Molecular imprinting technology (MIT) which arises from molecular recognition is now a well-established technique for developing artificial receptors possessing strong affinity for specific target molecules. ${ }^{1-3}$ In the presence of a template, monomers are arranged and co-polymerized to form a cross-linked polymer. After removal of the template, a cavity complementary with the template in shape, size and interaction is left. In general, the imprinting process involved three basic steps: 1) formation of the complex between template and functional monomers; 2) polymerization of the complex in the presence of a cross-linking agent; 3 ) removal of the template from the formed polymer by extraction, leaving specific cavities which can selectively adsorb the templates. ${ }^{4,5}$

Compared to biological receptors, imprinted materials possess inherent advantages like: 1) easy preparation; 2) good mechanical stability due to highly cross-linked structure; 3) repeated uses without loss of molecular recognition capability. ${ }^{6,7}$ So, they have potential application in many fields, such as chromatography, ${ }^{8,9}$ sensors, ${ }^{10,11}$ and solid-phase extraction..$^{9,12}$ So far, most MIPs are obtained through

*For correspondence radical polymerization. ${ }^{13-16}$ These polymerizations are extensively used in imprinted field and have satisfactory results. But this method requires a severe condition in preparation process.

A sol-gel method is another strategy to prepare MIPs. ${ }^{17-21}$ Compared to the radical polymerization method, the sol-gel method has some advantages: 1) MIPs could be synthesized under mild conditions; 2) different morphologies could be obtained, e.g., bulk solids, fibers, films, etc.; 3) the surface of the cavity could be easily modified with organic groups; 4) obtained polymer possesses several superiorities in physical aspect, as they exhibit porous, rigid, good optical properties. ${ }^{22,23}$

2, 4-Dichlorophenoxyacetic acid (2, 4-D) is a chief component of commonly used herbicides which has been frequently detected in water. It is harmful to human beings and threatens our health. ${ }^{24,25}$ Recently, there are many reports about molecularly imprinted polymer for 2, 4-dichlorophenoxyacetic acid. ${ }^{26-29}$ Han et al. have reported a surface-imprinted aminofunctionalized silica gel sorbent for 2, 4-D using silica gel as the support, aminopropyltriethoxysilane (APTES) and tetraethoxysilane (TEOS) as reacting monomers. ${ }^{29}$ The procedure of bulk polymerization is simple and results are relatively satisfactory. Here, we employed bulk polymerization using tetraethoxysilane 
(TEOS) as a cross-linking agent, phenyltrimethoxysilane (PTMOS), aminopropyltriethoxysilane (APTES) as functional monomers to synthesize a sol-gel-based MIP for selective adsorption of 2, 4-D in the present study. Results showed that MIPs fabricated by this method possess a better selectivity to $2,4-\mathrm{D}$.

\section{Experimental}

\subsection{Reagents and apparatus}

2, 4-Dichlorophenoxyacetic acid (2, 4-D, 99\%+), 2, 4-dichlorophenylacetic acid (DCPA, 98\%+) phenoxyacetic acid (PA, 99\%+), and 2,4-dichlorophenol(DCP, $99 \%+$ ) were purchased from ACROS. Tetraethoxysilane (TEOS, AR) was purchased from Tianjin Damao Chemical Reagent Factory, China. Phenyltrimethoxysilane (PTMOS, 98\%), and aminopropyltriethoxysilane (APTES, 98\%) were purchased from Sigma-Aldrich Co.

Adsorption spectra and optical densities of solutions were recorded using a Shimadzu UV-2550 spectrophotometer. The FT-IR spectra $\left(4000-400 \mathrm{~cm}^{-1}\right)$ in $\mathrm{KBr}$ were recorded by VERTEX-70 infrared spectrometer. HPLC analysis was performed on a Shimadzu system with LC-20AT pump, DGU-20A5 online degasser system, SPD-20A UV-detector, SIL-10AF auto sampler and a reverse phase C18 VP-ODS column $(250 \times$ $4.6 \mathrm{~mm}, 5 \mu \mathrm{m})$. The mobile phase was composed of methanol/water $(7: 3, \mathrm{~V} / \mathrm{V})$, and its flow rate was $1 \mathrm{~mL}$ $\min ^{-1}$.

\subsection{Preparation of MIPs}

Figure 1 depicts the development of MIPs. In the procedure, three monomers (TEOS, $20 \mathrm{mmol}$; APTES, $1.5 \mathrm{mmol}$; PTMOS, $1 \mathrm{mmol}$ ) were first mixed with $5.0 \mathrm{~mL}$ ethanol in a $50 \mathrm{~mL}$ glass beaker until homogenity, followed by addition of $150 \mu \mathrm{l}$ concentrated hydrochloric acid and $1.5 \mathrm{~mL}$ distilled water. The resultant mixture was kept stirring at $30^{\circ} \mathrm{C}$ for $30 \mathrm{~min}$. After that, the template 2, 4-D was added into the solution and the reaction going for another $2.5 \mathrm{~h}$. Finally, the obtained gel was dried at $80^{\circ} \mathrm{C}$ for $12 \mathrm{~h}$ in a vacuum oven to form a sol-gel monolith. The resultant monolith was then crushed and Soxhlet extracted first with ethanol/acetic acid (9:1, v/v) for $12 \mathrm{~h}$ and then with ethanol for $8 \mathrm{~h}$ to remove any unreacted reagents and the template. For comparison, the non-imprinted polymer (NIP) was also prepared under the same conditions with the exception that no template was added.

\subsection{Measurement of adsorption capacities}

In a $5 \mathrm{~mL}$ plastic tube, $10.0 \mathrm{mg}$ MIP or NIP was mixed with $2.0 \mathrm{~mL} \mathrm{2,4-D}$ solution of a known concentration $\left(\mathrm{C}_{0}\right)$ and $\mathrm{pH}$. The mixtures were then kept shaking in a thermostatic shaker bath until an equilibrium was reached at $30^{\circ} \mathrm{C}$. After centrifugation, the supernate was filtered with porous membrane (pore size $=0.45 \mu \mathrm{m}$ ), the concentration $\left(\mathrm{C}_{\mathrm{e}}\right)$ of 2, 4-D in the filtrate was then determined with a UV-visible spectrophotometer at $\lambda=283 \mathrm{~nm}$. These experiments were conducted in triplicate, and an average was used for the calculation of the adsorption capacity. The amount of 2, 4-D adsorbed by MIP or NIP was obtained by following equation:

$$
\mathrm{Q}_{\mathrm{e}}=\frac{V\left(C_{0}-C_{e}\right)}{m}
$$

where $\mathrm{Q}_{e}(\mathrm{mg} / \mathrm{g})$ is adsorption capacity at equilibrium, $\mathrm{V}(\mathrm{L})$ is the volume of the 2, 4-D solution and $\mathrm{m}(\mathrm{g})$ is the weight of the adsorbent.

The selectivity coefficient $\mathrm{K}$ was obtained using equation (2).

$$
\mathrm{K}=\mathrm{Q}_{\mathrm{MIP}} / \mathrm{Q}_{\mathrm{NIP}}
$$

$\mathrm{Q}_{\mathrm{MIP}}$ and $\mathrm{Q}_{\mathrm{NIP}}$ were the adsorption capacities of MIP and NIP toward 2, 4-D, respectively.

The relative selectivity coefficient $\mathrm{K}^{\prime}$ was obtained using equation (3).

$$
\mathrm{K}^{\prime}=\mathrm{Q}_{\mathrm{MIP}, 2,4-\mathrm{D}} / \mathrm{Q}_{\mathrm{MIP}, \text { analogue }}
$$

$\mathrm{Q}_{\mathrm{MIP}, 2,4-\mathrm{D}}$ and $\mathrm{Q}_{\mathrm{MIP}, \text { analogue }}$ were the adsorption capacities of MIP toward 2, 4-D, and MIP toward 2, 4-D' analogues respectively in competitive adsorption.

To study the effect of incubation parameters such as medium $\mathrm{pH}$, incubation time, etc. on the adsorption capacity of MIP or NIP toward 2, 4-D, batch experiments under similar conditions were conducted using the same procedure mentioned above. Detailed conditions were given in the figures or tables.

\section{Results and discussions}

\subsection{Preparation and FT-IR characterization of MIPs}

Different compositions of MIPs labeled as P1-P13 (table 1) were obtained. Of the three precursors, TEOS acted as cross-linking agent, PTMOS and APTES acted as functional monomers. Both PTMOS and APTES were involved in the gelation process in addition to immobilizing the template molecule 2, 4-D. It is believed that PTMOS interacts with the template 2, 4-D through hydrophobicity and $\pi-\pi$ stacking, but APTES interacts with 2, 4-D through electrostatic interaction and hydrogen bond. 

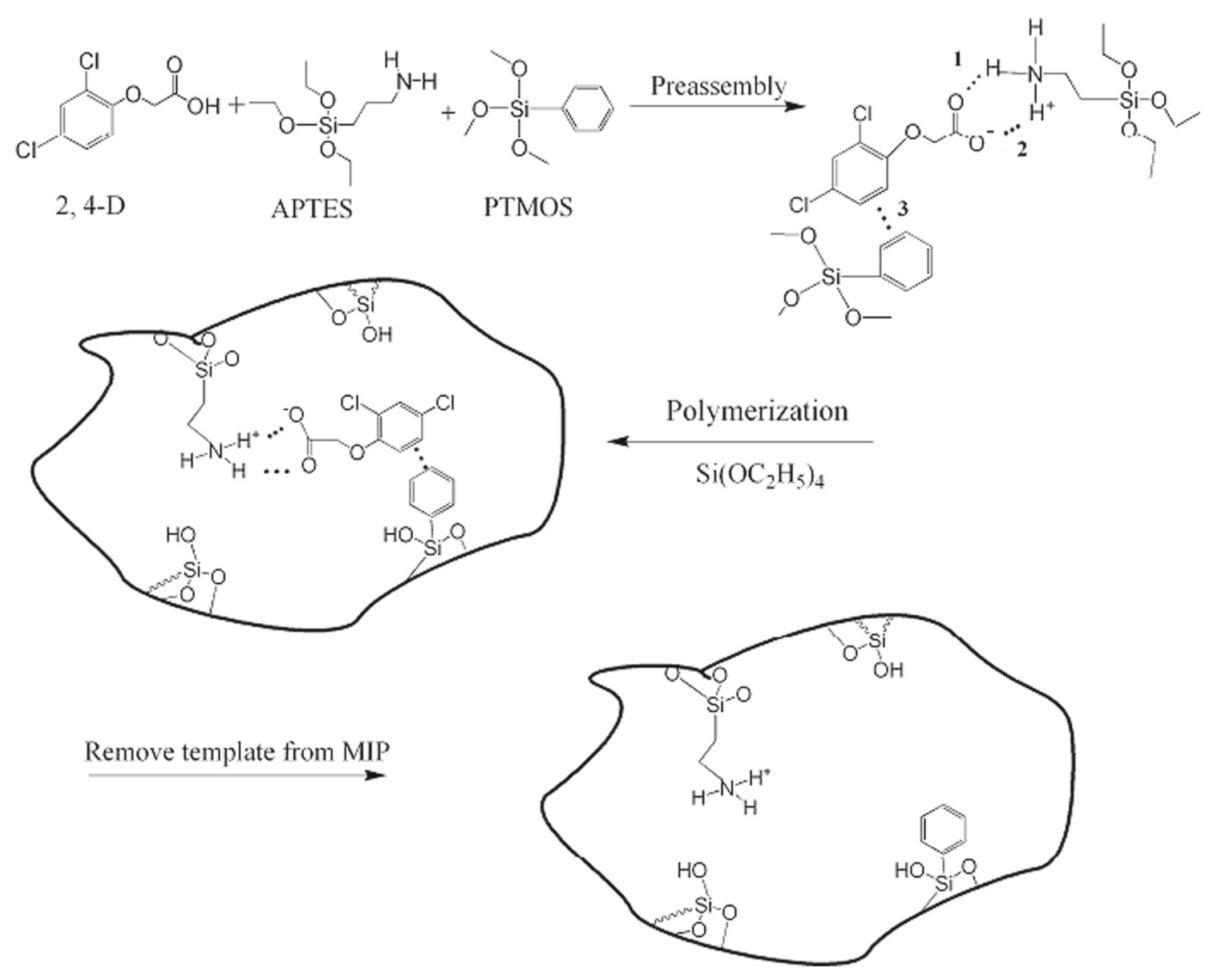

Figure 1. Schematic representation of preparation of MIPs: 1. Hydrogen bond force 2. Electrostatic interaction force 3 . Hydrophobicity and $\pi-\pi$ stacking force.

The FT-IR spectra of P3 and its corresponding NIP were shown in figure $2 \mathrm{a}$. The broad peaks at ca. $3250 \mathrm{~cm}^{-1}$ is due to the stretching vibrations of $\mathrm{O}-\mathrm{H}$ (residual $\mathrm{Si}-\mathrm{OH}$ and adsorbed water), $\mathrm{N}-\mathrm{H}$ and $\mathrm{C}-\mathrm{H}$. Peaks at $1650 \mathrm{~cm}^{-1}$ and $1560 \mathrm{~cm}^{-1}$ originated from O$\mathrm{H}$ and N-H bending vibrations. Peaks at ca. $1100 \mathrm{~cm}^{-1}$ and $976 \mathrm{~cm}^{-1}$ are attributed to the stretching vibrations of Si-O-Si and Si-O-H, and the peaks at ca. $780 \mathrm{~cm}^{-1}$ and $490 \mathrm{~cm}^{-1}$ result from $\mathrm{Si}-\mathrm{O}$ bending vibrations. It can be seen that the spectrum of P3 is very similar to that of its NIP, indicating that the templates 2, 4-D have been removed completely.

On comparison of the FT-IR spectra of P3, P6 and P10 (figure 2b), it is found that the spectrums of P6 is different from P3 or P10 (the latter two is very similar in sharp, peak position and peak intensity) at $1560 \mathrm{~cm}^{-1}$ which originated from N-H bending vibrations. This is due to the absence of $-\mathrm{NH}_{2}$ group in $\mathrm{P} 3$, which correspond to their compositions.

\subsection{Parameters affecting the selectivity coefficients $K$ of MIPs}

3.2a The proportion of three kinds of monomers: Figure 3 shows the selective adsorption of different MIPs. It can be seen that both APTES and PTMOS have great impacts on $\mathrm{Q}_{e}$ and selectivity coefficients

Table 1. Molar compositions of the 3 monomers for the preparation of the 13 samples.

\begin{tabular}{lccccccccccccc}
\hline Samples & P1 & P2 & P3 & P4 & P5 & P6 & P7 & P8 & P9 & P10 & P11 & P12 & P13 \\
\hline TEOS(mmol) & 10 & 15 & 20 & 30 & 40 & 20 & 20 & 20 & 20 & 20 & 20 & 20 & 20 \\
APTES(mmol) & 1.5 & 1.5 & 1.5 & 1.5 & 1.5 & 0 & 1 & 2 & 2.5 & 1.5 & 1.5 & 1.5 & 1.5 \\
PTMOS(mmol) & 1 & 1 & 1 & 1 & 1 & 1 & 1 & 1 & 1 & 0 & 0.5 & 1.5 & 2 \\
\hline
\end{tabular}

*The amount of 2, 4-D was kept at $0.4 \mathrm{mmol}$. 

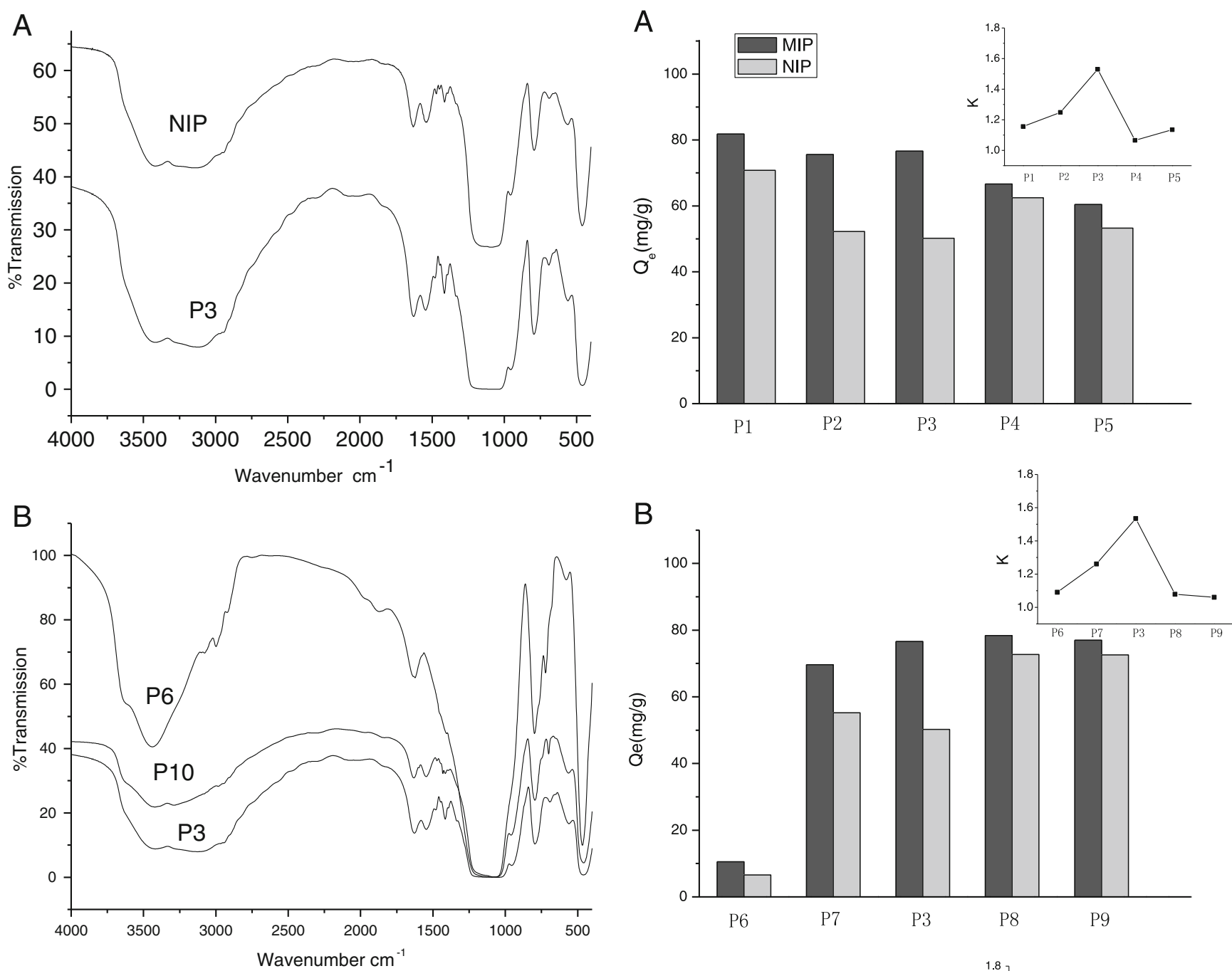

Figure 2. FT-IR spectra of polymers $\mathrm{P} 3$ and its corresponding NIP (a) P3, P6 and (b) P10.

$\mathrm{K}$, but the APTES dependent changes were larger than the PTMOS dependent changes; i.e., the APTES seems to play a more important role than PTMOS does in building-up process of MIPs. The best $\mathrm{Q}_{\mathrm{e}}$ and $\mathrm{K}$ values occurred at the molar ratio of 20:1.5:1 (TEOS: APTES: PTMOS).

3.2b The amount of 2, 4-D: It can also be found that the amount of the template 2, 4-D has some influences on the performance of MIPs (table 2). At low concentration of 2, 4-D, the adsorption capacity of MIPs increased with the increase of the amount of 2, 4-D. When the molar ratio value of the monomers to the template reached 6.25, the MIPs had a maximum adsorption capacity. This trend may be related to the microstructure of the MIPs. It is accepted that the fewer the templates, the smaller the porosity of MIPs. In the

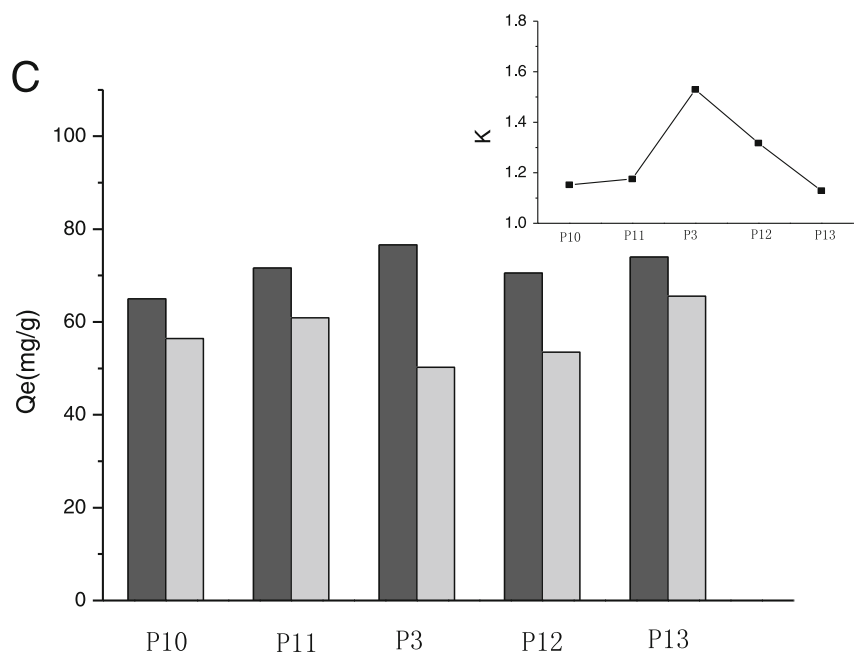

Figure 3. Effects of a change of the amount of one of the three monomers on the performance of MIPs (a) TEOS varied, (b) APTES varied, (c) PTMOS varied.

presence of large amount of templates, the structure of MIP becomes too loose to be able to maintain a three-dimensional structure of the cavities. 
Table 2. Effect of the amount of 2, 4-D on the performance of MIPs.

\begin{tabular}{lccccc}
\hline $\begin{array}{l}\text { Monomers } \\
(\mathrm{mmol})\end{array}$ & $\begin{array}{c}\text { template } \\
(\mathrm{mmol})\end{array}$ & $\begin{array}{c}\text { monomers/ } \\
\text { template }\end{array}$ & $\begin{array}{c}\text { QMIP } \\
(\mathrm{mg} / \mathrm{g})\end{array}$ & $\begin{array}{c}\mathrm{Q}_{\mathrm{NIP}} \\
(\mathrm{mg} / \mathrm{g})\end{array}$ & $\mathrm{K}$ \\
\hline 2.5 & 0.2 & 12.50 & 64.9 & 50.2 & 1.29 \\
2.5 & 0.3 & 8.33 & 69.4 & 50.2 & 1.38 \\
2.5 & 0.4 & 6.25 & 76.6 & 50.2 & 1.53 \\
2.5 & 0.5 & 5.00 & 65.1 & 50.2 & 1.30 \\
2.5 & 0.6 & 4.17 & 72.8 & 50.2 & 1.45 \\
\hline
\end{tabular}

3.2c The molar ratio of $\mathrm{H}_{2} \mathrm{O}$ to the precursors: The amount of the precursors (including TEOS, APTES, PTMOS) influences the performance of MIPs. Table 3 shows the effect of the molar ratio of $\mathrm{H}_{2} \mathrm{O}$ to the precursors $\left(\mathrm{H}_{2} \mathrm{O} / \mathrm{Si}\right)$ on the performance of MIPs. In solgel process, the amount of water is a key parameter that determines the structure and properties of the MIPs. The maximum value of $\mathrm{K}$ occurs at a $\mathrm{H}_{2} \mathrm{O} / \mathrm{Si}$ ratio of ca.4. If $\mathrm{H}_{2} \mathrm{O} / \mathrm{Si}$ is small, there will be a large number of organic group residues on the surface which cannot participate in hydrolysis. It is these residuals that lead to a large adsorption capacity for both MIP and NIP, and therefore lower the $\mathrm{K}$ values. When the $\mathrm{H}_{2} \mathrm{O} / \mathrm{Si}$ is large, the excessive water that does not participate in the hydrolysis will act as a pore-forming agent and remain in the gel. After evaporation, non-specific binding cavities are formed, resulting in lower $\mathrm{K}$ values.

\section{2d The molar ratio of $\mathrm{CH}_{3} \mathrm{CH}_{2} \mathrm{OH}$ to the precursors:} Ethanol was used here as a co-solvent which not only enabled uniform mixing of water and monomers but also affected the sol viscosity and gelation time. It is advised that the amount of ethanol added should be kept at a moderate value due to the fact that small amount of ethanol will result in immiscibility of the monomers with water, but large amount of ethanol will inhibit the hydrolysis reaction (ethanol is a by-product of the hydrolysis). Table 4 shows that the maximum value of $\mathrm{K}$ occurs at the ratio of ethanol to monomer between 2 and 4.

Table 3. Effect of the molar ratio of $\mathrm{H}_{2} \mathrm{O}$ to the precursors on the performance of MIPs.

\begin{tabular}{lccccc}
\hline $\begin{array}{l}\text { Precursors } \\
(\mathrm{mmol})\end{array}$ & $\begin{array}{c}\mathrm{H}_{2} \mathrm{O} \\
(\mathrm{mmol})\end{array}$ & $\begin{array}{c}\mathrm{H}_{2} \mathrm{O} / \\
\text { precursors }\end{array}$ & $\begin{array}{c}\mathrm{Q}_{\mathrm{MIP}} \\
(\mathrm{mg} / \mathrm{g})\end{array}$ & $\begin{array}{c}\mathrm{Q}_{\mathrm{NIP}} \\
(\mathrm{mg} / \mathrm{g})\end{array}$ & $\mathrm{K}$ \\
\hline 22.5 & 27.8 & 1.24 & 77.4 & 72.1 & 1.07 \\
22.5 & 83.3 & 3.70 & 76.6 & 50.2 & 1.53 \\
22.5 & 138.9 & 6.17 & 78.6 & 61.1 & 1.28 \\
22.5 & 194.4 & 8.64 & 78.1 & 67.3 & 1.16 \\
\hline
\end{tabular}

Table 4. Effect of the molar ratio of $\mathrm{CH}_{3} \mathrm{CH}_{2} \mathrm{OH}$ to the precursors on the performance of MIPs.

\begin{tabular}{lccccc}
\hline $\begin{array}{l}\text { Precursor } \\
(\mathrm{mmol})\end{array}$ & $\begin{array}{c}\mathrm{CH}_{3} \mathrm{CH}_{2} \mathrm{OH} \\
(\mathrm{mmol})\end{array}$ & $\begin{array}{c}\mathrm{CH}_{3} \mathrm{CH}_{2} \mathrm{OH} / \\
\text { precursors }\end{array}$ & $\begin{array}{c}\mathrm{Q}_{\mathrm{MIP}} \\
(\mathrm{mg} / \mathrm{g})\end{array}$ & $\begin{array}{c}\mathrm{Q}_{\mathrm{NIP}} \\
(\mathrm{mg} / \mathrm{g})\end{array}$ & $\mathrm{K}$ \\
\hline 22.5 & 51.5 & 2.29 & 70.1 & 52.7 & 1.33 \\
22.5 & 68.6 & 3.05 & 69.6 & 51.5 & 1.35 \\
22.5 & 85.8 & 3.81 & 76.6 & 50.2 & 1.53 \\
22.5 & 103.0 & 4.58 & 70.3 & 66.0 & 1.07 \\
22.5 & 120.1 & 5.34 & 73.5 & 66.5 & 1.11 \\
\hline
\end{tabular}

\subsection{Parameters affecting the adsorption performance of MIPs}

3.3a Incubation time: Figure 4 shows that the amount of 2, 4-D adsorption on P3 increases with time. It is shown that the adsorption capacity increases first rapidly and then it remains constant after a contact time of $3 \mathrm{~h}$. Adsorption equilibrium can be reached in a relatively short period of time, indicating the stronger force and the less mass transfer resistance between P3 and 2, 4-D.

3.3b pH of media: The $\mathrm{pH}$ value of the 2, 4-D solution is an important parameter that affects the adsorption of MIPs toward 2, 4-D because the charges of the functional groups on 2, 4-D as well as on MIPs vary with the $\mathrm{pH}$ value (the hydrophobic interaction and $\pi-\pi$ stacking between $2,4-\mathrm{D}$ and $\mathrm{P} 3$ seemed to be not sensitive to the $\mathrm{pHs}$ ). As shown in figure 5, the maximum adsorption capacity of $\mathrm{P} 3$ toward 2, 4-D appears at $\mathrm{pH} \approx 7$. At low $\mathrm{pHs}$, the - $\mathrm{COOH}$ of $2,4-\mathrm{D}$ can hardly dissociate, so few anions are produced and the contribution from the electrostatic attraction of cationic $-\mathrm{NH}_{3}^{+}$of

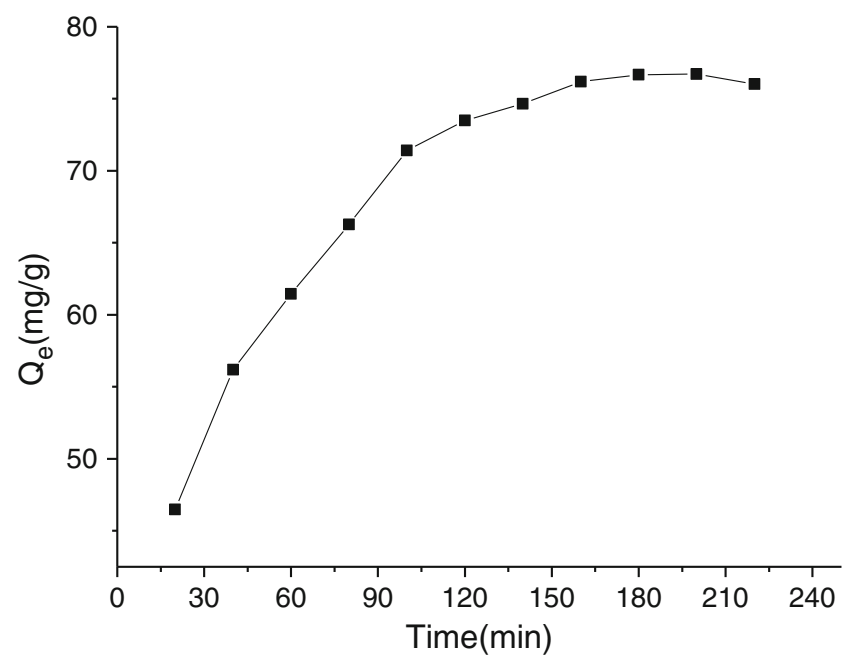

Figure 4. The time-dependent adsorption curve of 2, 4-D on $\mathrm{P} 3\left(\mathrm{C}_{0}=2 \mathrm{mmol} / \mathrm{L}, \mathrm{T}=30^{\circ} \mathrm{C}, \mathrm{pH}=7\right)$. 


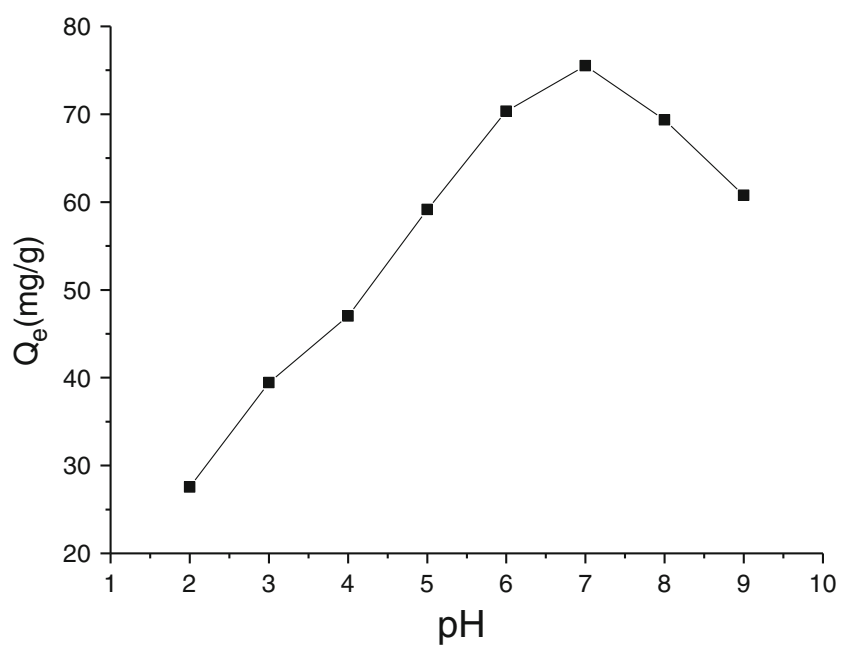

Figure 5. Influence of the solution $\mathrm{pHs}$ on the adsorption of $2,4-\mathrm{D}$ on $\mathrm{P} 3\left(\mathrm{C}_{0}=2 \mathrm{mmol} / \mathrm{L}, \mathrm{T}=30^{\circ} \mathrm{C}, \mathrm{t}=12 \mathrm{~h}\right)$.

MIP toward 2, 4-D is therefore small. While at high $\mathrm{pH}$ values, the dissociation degree of $-\mathrm{COOH}$ increases but the protonization degree of the $-\mathrm{NH}_{2}$ on $\mathrm{P} 3$ decreases; the electrostatic interaction is also weak and the adsorption capacity of P3 toward 2, 4-D reduced greatly. At $\mathrm{pH} \approx 7$, more cations and anions were produced, which resulted in a strongest electrostatic interaction between 2, 4-D and MIP. And therefore, a maximum $\mathrm{Q}_{\mathrm{e}}$ was attained.

\subsection{Selectivity of P3 for 2, 4-D over the structurally similar compounds}

2, 4-dichlorophenylacetic acid (DCPA) and 2, 4dichlorophenol (DCP) that structurally similar to 2 , 4-D were chosen as the analogues of 2, 4-D and the selectivity of P3 was investigated in a competitive binding experiment using an aqueous 2, 4$\mathrm{D}, 2$, 4-dichlorophenylacetic acid (DPAC) and 2, 4-dichlorophenol (2, 4-DCP) mixture. The result (figure 6) showed that $\mathrm{P} 3$ has highly larger adsorption capacities for 2, 4-D over DCPA and DCP. The ratio of capacities of 2, 4-D and DCP on P3 (K') reached 28.15 which indicated that the polymers possess good selectivity.

\subsection{Adsorption mechanism}

Adsorption isotherms are helpful for understanding the adsorption mechanism. Figure 7 was the plots of the equilibrium adsorption capacity of $\mathrm{P} 3$ and its corresponding NIP toward 2, 4-D versus the initial concentration of 2, 4-D.

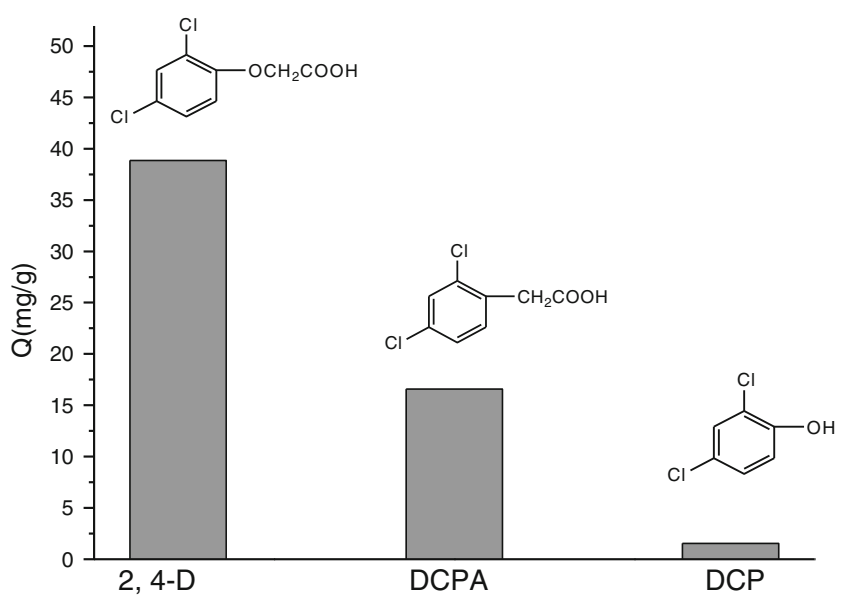

Figure 6. The competitive adsorption capacities of $\mathrm{P} 3$ toward 2, 4-D and its analogues $\left(\mathrm{T}=30^{\circ} \mathrm{C}, \mathrm{t}=12 \mathrm{~h}\right.$, $\mathrm{pH}=7)$.

Followed, adsorption isotherm model Langmuir equation was used to fit the data. According to Langmuir equation:

$$
\frac{C_{e}}{Q_{e}}=\frac{1}{Q_{\max } K_{L}}+\frac{C_{e}}{Q_{\max }}
$$

where $\mathrm{C}_{\mathrm{e}}(\mathrm{mg} / \mathrm{L})$ is the equilibrium concentration of 2 , 4-D, $\mathrm{Q}_{\mathrm{e}}(\mathrm{mg} / \mathrm{g})$ is the amount of 2, 4-D adsorbed on MIPs at a given concentration, $Q_{\max }(\mathrm{mg} / \mathrm{g})$ is the $\max -$ imum adsorption capacity, and $\mathrm{K}_{\mathrm{L}}(\mathrm{L} / \mathrm{mg})$ is Langmuir constant related to the affinity of the binding sites on MIPs. When $\mathrm{C}_{\mathrm{e}} / \mathrm{Q}_{\mathrm{e}}$ was plotted against $\mathrm{C}_{\mathrm{e}}, \mathrm{K}_{\mathrm{L}}$ and $\mathrm{Q}_{\max }$ could be obtained via a linear regression. In our system, the $\mathrm{Q}_{\max }$ and $\mathrm{K}_{\mathrm{L}}$ were determined to be $243.3 \mathrm{mg} / \mathrm{g}$ and

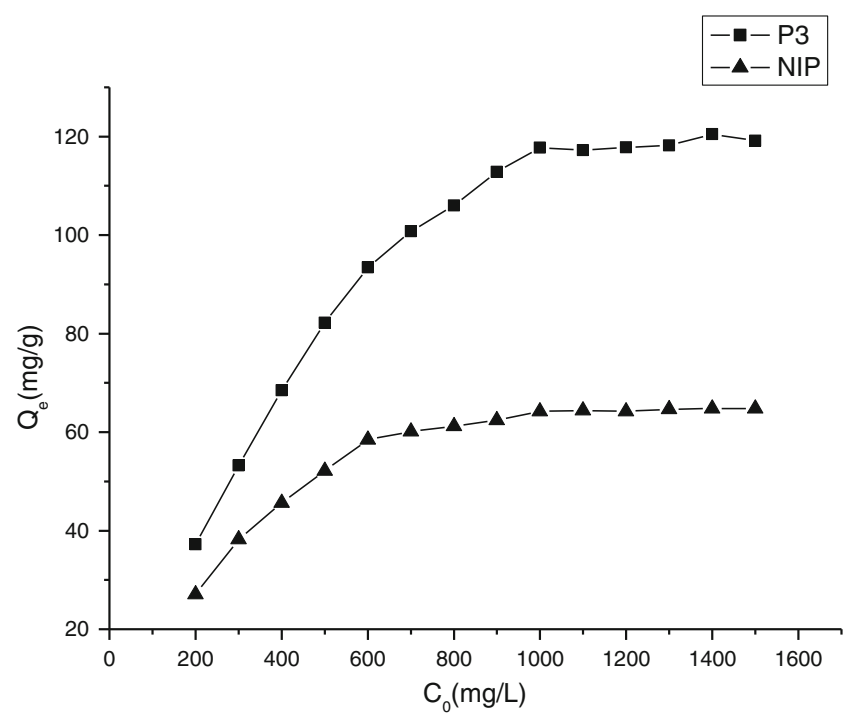

Figure 7. The change of the adsorbing capacities of $\mathrm{P} 3$ with the initial concentration of $2,4-\mathrm{D}\left(\mathrm{T}=30^{\circ} \mathrm{C}, \mathrm{t}=12 \mathrm{~h}\right.$, $\mathrm{pH}=7$ ). 


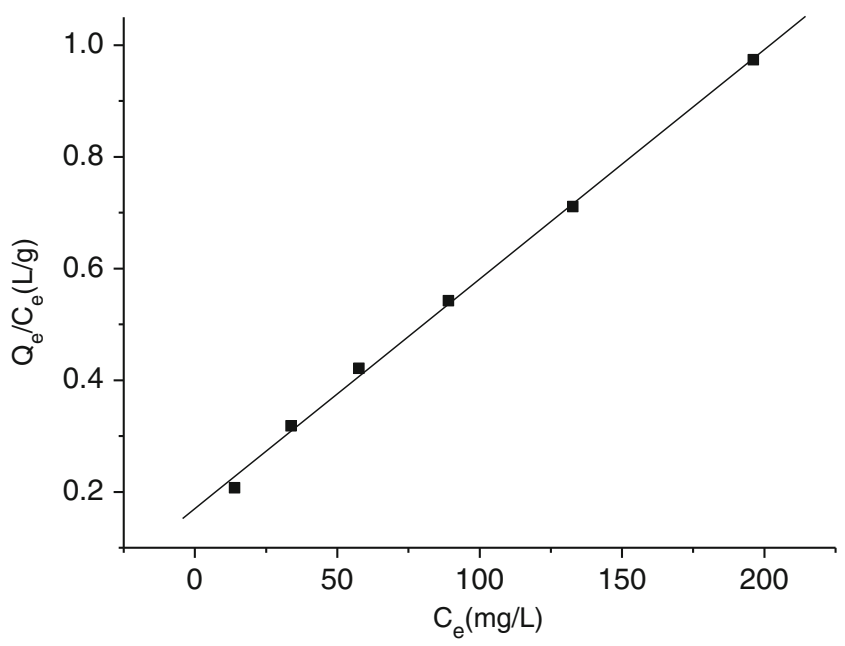

Figure 8. Langmuir adsorption isotherm for the adsorption of 2, 4-D on P3.

Table 5. Extraction recyclability through five extraction/ stripping cycles.

\begin{tabular}{lccccc}
\hline Extraction cycles & 1 & 2 & 3 & 4 & 5 \\
\hline Adsorption capacity & 76.59 & 75.91 & 75.12 & 74.08 & 72.86 \\
R (\%) & 100 & 99.11 & 98.08 & 96.72 & 95.13 \\
\hline
\end{tabular}

$0.0242 \mathrm{~L} / \mathrm{mg}$, respectively (figure 8 ). The adsorption well-represented by Langmuir isotherm indicated that 2, 4-D on MIPs was monolayer adsorption.

\subsection{Repeated use of MIPs}

The 2, 4-D saturated MIP (P3) was Soxhlet extracted first with a mixed solvent (ethanol: acetic acid: water $=7: 2: 1)(12 \mathrm{~h}$, twice $)$, followed by ethanol $(12 \mathrm{~h}$, twice). After centrifugation, the resulting P3 was dried and then transferred into new tubes for the adsorption experiment. Results (table 5) showed that the adsorption capacity of P3 remained almost unchanged after several recycles, indicating its good reusability.

\section{Conclusions}

In the present study, TEOS, APTES and PTMOS were selected to synthesize an MIP toward 2, 4-D based on the hydrogen bonding and electrostatic attraction between APTES and 2, 4-D as well as the hydrophobicity and $\pi-\pi$ stacking between PTMOS and 2, 4-D. Our results showed that in addition to the molar ratio of the three monomers, the amount of the templates, water and ethanol had great effects on the adsorption performance of the prepared MIPs with the optimum molar ratios of TEOS to APTES to PTMOS, of $\mathrm{H}_{2} \mathrm{O}$ to the three monomers, and of ethanol to the three monomers being 20:1.5:1, ca. 4, and ca. 4, respectively. The MIP prepared under optimum conditions (P3) had large adsorption capacity and high selectivity. The adsorption of 2, 4-D on P3 obeyed Langmuir model.

\section{References}

1. Steinke J, Sherrington D C and Dunkin I R $1995 A d v$. Polym. Sci. 12381

2. Mayes A G and Mosbach 1997 Trends Anal. Chem. 16 321

3. Andersson L I 2000 J. Chromato. B 7453

4. Urraca J L, Carbajo M C, Torralvo M J, GonzalezVazquezc J, Orellanad G M and Moreno-Bondia C 2008 Biosens. Bioelectron. 24155

5. Kriz D, Kempe M and Mosbach K 1996 Sens. Actuat. B 33178

6. Ansell R J, Kriz D and Mosbach K 1996 Curr. Opin. Biotech. 789

7. Piletsky S A, Alcock S and Turner A P F 2001 Trends Biotech. 199

8. Tamayo F G, Turiel E and Martin-Esteban A $2007 \mathrm{~J}$. Chromato. A 115232

9. Wang S, Xu Z X, Fang G Z, Zhang Y and He J X 2008 J. Sep. Sci. 311181

10. Yeh W M and Ho K C 2005 Analytic. Chimica Acta 542 76

11. Patel A K, Sharma P S and Prasad B B 2009 Int. J. Pharma 37147

12. Zhu X L, Yang J, Su Q D, Cai J B and Gao Y $2005 J$. Chromato. A 1092161

13. Lu Y, Li C X, Wang X D, Sun P C and Xing X H 2004 J. Chromato. B 80453

14. Cacho C, Turiel E and Perez-Condea C 2009 Talanta 78 1029

15. Bjarnason B, Chimuka L and Ramstrom O 1999 Analytic. Chem. 712152

16. Caro E, Marce R M, Cormack P A G, Sherrington D C and Borrull F 2005 Analytic. Chimica Acta 55281

17. Diaz-Garcia M E and Laino R B 2005 Microchimica Acta 14919

18. Dickey F H 1949 Proc. Natl. Acad. Sci. 35227

19. Hsu C W and Yang M C 2008 Sens. Actuat. B 134680

20. Marx S and Liron Z 2001 Chem. Mat. 133624

21. Olwill A, Hughes H, O'Riordain M and McLoughlin P 2004 Biosens. Bioelectr. 201045

22. Gupta R and Kumar A 2008 Biotech. Adv. 26533

23. E Lofgreen J and A Ozin G 2014 Chem. Soc. Rev. 43911

24. Yu Y H, Ma J and Hou Y J 2006 J. Env. Sci. 181043

25. Ayar N, Bilgin B and Atun G 2008 Chem. Engn. J. 138 239

26. Liu Y L, He Y H, Jin Y L, Huang Y Y, Liu G Q and Zhao R 2014 J. Chromato. A 132311

27. Yang W J, Jiao F P, Zhou L, Chen X Q and Jiang X Y 2013 App. Surf. Sci. 284692

28. Jiang G S, Zhong S A, Chen L, Blakey L and Whitaker A 2011 Rad. Phys. Chem. 80130

29. Han D M, Jia W P and Liang H D 2010 J. Env. Sci. 22 237 